\title{
Identidades culturales, globalidad y sociedad de la información
}

Maria de la Luz Casas Pérez ${ }^{1}$

La sociedad debe definir su identidad, su articulación, el mundo, sus relaciones con él y con los objetos que contiene, sus necesidades y sus deseos. Sin la respuesta a estas preguntas, sin estas definiciones, no hay mundo humano, ni sociedad, ni cultura - pues todo quedaría en un caos indiferenciado.

Cornelius Castoriadis

\section{Presentación}

El presente trabajo tiene por objetivo revisar las aproximaciones conceptuales sobre la identidad cultural en la era de la globalidad, y más específicamente, la revisión del concepto de la identidad nacional mexicana a fin de siglo y fin de milenio en el contexto de un mundo globalizado y de la nueva sociedad de la información.

Las premisas sobre las cuales se trabajará este documento, tienen que ver con los conceptos centrales de la identidad, sus distinciones con otros conceptos relacionados como la identidad nacional y la identidad cultural, con la globalización y sus características específicas, y por último con los procesos de construcción-deconstrucción de las identidades a la luz de la nueva sociedad de la información.

1. ITESM. Campus Morelos.mcasas@campus.mor.itesm.mx 


\section{Introducción}

A más de quinientos años del descubrimiento de América, el hombre moderno todavía se maravilla del hecho de que el mundo sea redondo y no plano; a más de cien años del descubrimiento de la electricidad, todavía nos admiramos de que podamos estar en contacto unos con los otros a la velocidad de la luz; a más de cincuenta años de la puesta en marcha de la televisión comercial, hemos descubierto que las mismas imágenes circulan alrededor del globo terráqueo. ¿Por qué hasta ahora es que entramos en esta conciencia de que las condiciones de estructuración de nuestros espacios de convivencia son distintas? ¿Es que el proceso en el cual nos sumergimos hace más de quinientos años apenas comienza a dar frutos? (Casas, 1998: 31-32).

Los frutos que está dando, lejos de ser uniformes son totalmente disímbolos. Es como si el árbol fuese injertado de tal manera que una de las ramas ofrece un fruto dulce y el otro ofrece uno más bien ácido. En una de las ramas está la uniformidad, la homogeneidad y en la otra está la heterogeneidad, la diferencia.

Así, la globalidad como producto de los grandes movimientos integradores de los capitales de finales del siglo XIX y del siglo XX, ha producido frutos diversos que son precisamente su consecuencia.

Ambas tienen el mismo origen, pero representan modos distintos de enfrentar un mismo proceso. Como diría García Canclini, ${ }^{2}$ son parte de los imaginarios con la que la globalización trabaja y de la interculturalidad que moviliza (García Canclini, 1999: 30). Pero además, y debido precisamente a la interculturalidad involucrada, en la medida en que los procesos globalizadores tienden a expandirse a otros mercados y a otros conjuntos socioculturales, tienen que trabajar con la heterogeneidad. ${ }^{3}$

Ahora bien, en términos de la interrelación entre lo social, lo cultural, lo político y lo comunicativo, la globalidad está provocando cuestiones específicas nunca antes vistas. Particularmente en el caso de sociedades que, como la mexicana, se han incorporado tardíamente a la constitución de lo global.

2. Néstor García Canclini ha hablado en numerosas ocasiones de la globalidad, y de su conjunción con lo local. Su última obra sobre el particular es: Néstor García Canclini. La globalización imaginada. Editorial Paidós, 1999. Una entrevista muy interesante sobre el particular ver: Catalina Galla y Marta Rizo, "Hay que reconocer la diferencia y ver qué se puede hacer con ella" en Portal de la Comunicación. Institut de la Comunicació de la UAB. Universidad de Barcelona, 2001. en: http://www.blues.uab.es/olympic.studies/portal/122641/entre/c anclini/canclinj.pdf.

3. Catalina Galla y Marta Rizo, "Hay que reconocer la diferencia y ver qué se puede hacer con ella" en Portal de la Comunicación. Institut de la Comunicació de la UAB. Universidad de Barcelona, 2001. en: http://www.blues.uab.es/olympic.studies/portal/122641/entre/canclini/canclini.pdf. 
En ese sentido, la propia constitución de la nación mexicana se ha puesto en entredicho. La construcción de lo político, y el entramado básico que constituye a la nación mexicana ha experimentado un nuevo dibujo. Y es que, "la vida y el despliegue de las naciones son siempre procesos especificos" (Rivadeo, en Béjar Navarro, 1999: 184). En ese sentido por ejemplo, reconocemos que no podemos escapar a la política como única posibilidad de legitimar nuestra identidad nacional, pero además, como única posibilidad de trazarnos un modo de vida en común.

En el presente trabajo se exploran los límites la globalidad desde el punto de vista de lo político, pero también desde lo cultural y lo comunicativo, precisamente porque hacia finales de este siglo, la construcción de las identidades se ha visto influenciada por nuevas formas de definirnos a nosotros mismos.

\section{Los límites y las posibilidades de la globalidad}

Los propósitos de la proximidad a la que nos enfrenta la globalidad son múltiples. Tenemos que aprender a vivir en nuevos espacios, compartiendo los recursos. Las reacciones no son siempre las más deseables. La escasez del recurso material, la desigualdad, la marginación, la injusticia y la pobreza entre otros efectos de la globalidad, han venido acompañadas también de nacionalismos y fundamentalismos exacerbados.

Si bien no existe un modo de calificar a la globalización como la causa de todas estos movimientos sociales, es un hecho que la tecnología y las nuevas formas de alcanzar la inmediatez de la información a través de los modernos medios de comunicación, permite que nos percatemos de la presencia de estos movimientos de recomposición de los grupos, cuyas demandas remiten a la constitución misma de sus identidades y recuerda la manera ancestral en la que fueron definidos.

Independientemente de la forma en la que hayan sido concebidos, los fenómenos de identidad, se remiten a factores de etnocentrismo, conciencia de clase o identidad cultural, a través de los cuales el hombre se relaciona de manera natural con los que le son semejantes, y desconfía de los que le son diferentes.

Por otra parte, el contacto con las diferentes culturas, la formación de estereotipos, y otros factores, como bien apuntan los teóricos, son elementos que ayudan a la formación de identidades y, en ese sentido, los medios de comunicación ayudan a ampliar la gama de informaciones que tenemos a nuestro alcance y que nos permiten tener una experiencia del otro de manera 
indirecta. Así, finalmente, la percepción del otro puede ser alterada a través de las tecnologías y de los medios de comunicación.

La tecnología nos permite hoy en día responder a eventualidades de manera inmediata, los espacios se achican, las naciones se vuelven incapaces de lidiar con los grandes problemas mundiales. Como dice Daniel Bell, los Estados-nación son ahora demasiado pequeños para lidiar con los problemas globales y demasiado grandes para resolver los problemas locales (Giddens, 2000: 25). La globalidad como consecuencia de la integración es el correlato de la interdependencia. Lo que sucede hoy en cualquier parte del mundo, tiene repercusiones insospechadas en otras partes del planeta.

El deseo de extender los dominios del hombre no es nuevo (Mattelart, 1997); así el concepto de mundo conocido y de sus fronteras, es un aspecto recurrente, sin embargo, en este deseo de dominio planetario, por primera vez la tecnología nos permite llegar prácticamente a cualquier confín del globo terráqueo. Nos enfrentamos pues al escenario de la globalidad, en la que las posibilidades de abrir las fronteras e incidir en el otro, son ya una realidad y la tecnología por supuesto nos acompaña en el proceso.

La transformación económica en marcha, ha hecho realidad el viejo deseo de los economistas políticos por medio del cual los individuos en lugar de ser simplemente ciudadanos se conviertan en los grandes consumidores del mundo. Así, la extensión del mundo es posible gracias de la extensión de las actividades económicas (Casas, 1998: 34). Esta consideración es vigente hoy más que nunca, en la medida en que la tecnología es responsable de transformaciones en las relaciones de intercambio y consumo entre sujetos que no cuentan con características culturales semejantes.

De hecho, los productos que hoy en día circulan a través de las grandes redes de ensamblaje, producción y consumo son originarias de distintas latitudes, así como lo son los ciudadanos que habrán de consumirlos en distintas partes del mundo.

Dichos sujetos se convierten en objetos de relaciones que en un sentido los localiza como parte de un mismo grupo, pero en otro sentido los desterritorializa difuminando el tipo de identidad de la que gozaban y que de alguna manera los vinculaba a referentes tales como la lengua, la raza y el territorio, otrora vinculantes con una identidad; por otra parte, remite a otros procesos de interrelación sin los cuales la identidad no sería posible, como la comunicación. La identidad es central para toda referencia desde y hacia la comunicación. No podemos hablar de comunicación sin hablar del concepto de identidad como un elemento de y para la comunicación. La noción de identidad permite colocar al sujeto en contexto para la comunicación. Todas las otras referencias hacia lo local, lo nacional, lo internacional o lo global, se convierten en referentes para ubicar al sujeto en relación con otros. 
La presencia de los modernos medios de comunicación es un elemento sustancial de cambio para la transformación identitaria ya que extiende la presencia del yo y del otro, y permite traspasar las barreras de lo individual para acercarnos a la utopía de la globalidad.

No obstante, como dice García Canclini (1999: 28), en la globalización, los interlocutores de la comunicación son imprecisos, especialmente cuando se habla de los modernos medios de comunicación.

Pocas veces podemos imaginar un lugar preciso desde el cual nos hablan. Eso condiciona la sensación de que es difícil modificar algo, que en vez de ese programa de televisión o de ese régimen político podría haber otro... Sus diseños y sus decisiones se hacen en lugares inaccesibles, por estructuras organizacionales y no por personas.

Desde esta perspectiva, uno se pregunta si la identidad es creada por una interacción consciente en la que los interlocutores aprenden del otro para fundar así nuevas estructuras de diferenciación identitaria o si, por el contrario, nuestras identidades están hoy constituidas por marcos culturales definidos enteramente por las tendencias del mercado.

El propio García Canclini se plantea la necesidad de estudiar el consumo como manifestación de sujetos, donde se favorece su emergencia y su interpelación, o se propicia o se obstruye su interacción con otros sujetos (1999: 28). $\mathrm{Y}$ es que en un mundo globalizado se pierde la noción del otro; se sabe de la inevitable convivencia con el resto de los ciudadanos del mundo, pero al mismo tiempo a este otro no se le tiene presente, no se le conoce.

En los tiempos de la globalidad, se comienza a hablar del ciudadano del mundo, se empiezan a considerar los problemas de la gran "aldea global". No olvidemos, sin embargo que la utopía ha sido desenmascarada por los diferentes movimientos registrados en distintos puntos del planeta que reclaman el reconocimiento social y político a las identidades diversas.

La identidad sigue siendo el concepto central para hablar, ya sea desde la sociología o desde la psicología del yo frente a la alteridad, y en ese sentido, aún frente a la formación de los diversos grupos sociales, aún frente a la presencia de los viejos Estados-nación, para los sujetos sigue siendo indispensable reconocerse como diferente del otro.

El sujeto construye identidad por oposición al alter, y en términos generales se ubica a sí mismo como parte de los otros cuando comparte referentes comunes que no pueden sino provenir de procesos de comunicación diferenciados, en los que entran en juego otros referentes. Construimos identidades comunitarias, llámense éstas identidades nacionales o de otro tipo, por referencia a los otros, o por consenso con las características que nos son comunes, 
pero cuando los viejos conceptos de referencia se vuelven obsoletos, el proceso de construcción de identidades se altera.

La construcción de las identidades no es más un proceso de relación por contraposición con el alter, es más un proceso de inclusión fragmentaria a partir de elementos distanciados de identificación difusa. El sujeto es ya un número en la red, que entra y sale de los nuevos esquemas tecnológicos y mediáticos para la interrelación, pero que ya no se reconoce a sí mismo como parte de un grupo de manera específica. Sus procesos de construcción de identidades pasan por el fenómeno de la deconstrucción simbólica para la generación de nuevos referentes poco relacionados con un entorno material, sino que más bien abstracto, es decir las antiguas identidades colectivas, se han diluido.

García Canclini se pregunta si es posible organizar de otro modo los vínculos mediatizados, despegarnos de sus procedimientos de segregación y exclusión para auténticamente convertirnos en sujetos, pero la opción, dice él, no es defender la identidad o globalizarnos, sino entender las oportunidades de saber qué podemos hacer y ser con los otros, cómo encarar la heterogeneidad, la diferencia y la desigualdad.

Resulta paradójico pensar que paralelamente la globalidad se estén dando los movimientos de reconocimiento de las identidades diversas, y que, por otro lado, la tecnología esté haciendo posible cada vez más el contacto con el otro.

Gracias a las nuevas tecnologías de información, nuestro tránsito alternado entre lo local, lo nacional, lo mundial o lo global, se ha trastocado la manera misma en la que los seres humanos construimos identidades.

Existen sin embargo, numerosos factores que entran en juego en la conformación de las identidades. La lucha permanente entre la heterogeneidad y la homogeneidad, la distinción y la semejanza, el sentido de individualismo y el de comunidad, siguen estando presentes para el eterno dilema de la construcción social de las identidades.

Hoy en día visualizamos la creación de nuevos mitos fundacionales del orden social para la construcción de identidades, incluso desde la gestión de un "nuevo orden" económico, social y cultural, planteado desde el poder.

En este nuevo mito fundacional es el de la sociedad interconectada, de la sociedad globalizada en donde todos somos uno y el mismo, pero bajo la óptica de este nuevo mito fundacional, las identidades se convierten en un problema. Por un lado, el mito de la globalidad y de la sociedad de la información reclama al sujeto haciéndolo verdaderamente sujeto y explotando todas sus características individuales como distintas de los demás; pero por otro lado, la globalidad plantea el requisito de la gran comunidad en donde todos podemos coexistir pacíficamente. 
Hoy en día la identidad no debe ser atribuida exclusivamente a la adscripción a un grupo. La multiplicación de los mundos posibles implica que los sujetos pueden habitar diferentes esferas simultáneamente, pero también implica que existe un proceso de selección de los sujetos, a través del cual cada uno construye su propio repertorio de interacciones (Albrow, 1996: 150).

El tránsito de una esfera a otra, de lo individual a lo local, de lo local a lo regional o lo nacional y viceversa, no parece suficiente para explicar cómo podemos construir y deconstruir identidades. Como comentamos ya anteriormente, hoy en día hay muchas otras nociones que están siendo puestas en duda. El concepto del Estado-nación por ejemplo.

El Estado-nación, entendido como construcción social e histórica, había sido hasta hace pocos años, el referente dominante que le daba sentido a los procesos de producción y reproducción social. Muchos de nosotros crecimos en un mundo de estados nacionales configurado a partir de una geopolítica bipolar que funcionaba como un marco explicativo de la historia contemporánea. Hoy, en el umbral de un nuevo milenio de la era cristiana, donde las nuevas realidades se expresan con las palabras global, posmoderno e informático, no es exagerado decir que tenemos menos esquemas y seguridades (Béjar, 1999, contraportada).

Las ciencias sociales han registrado un viraje en el estudio de la temática individuo y sociedad. Ya no es suficiente analizar la estructura social o los agentes sociales para descubrir la mecánica de los movimientos sociales; resulta necesario retomar el concepto de la identidad y su relación con los grupos para establecer la posición relativa de los grupos dentro de una mecánica global (Albrow, 1996: 150).

La asignación de las identidades a partir de la identificación grupal es problemática, se sustenta sobre referentes que están cambiando. Los referentes anteriores, raza, religión, territorio, lengua, no son suficientes.

No basta la conciencia histórica para mantener una identidad nacional vigente. La conciencia histórica estaba hecha sobre la base de algunos referentes que ya no existen. La pureza de las razas, los himnos, los mitos, las tradiciones. Todo ello está siendo reinventado sobre la base de una historia de fin de siglo y de milenio en la cual todas las historias se interconectan unas con otras. Hoy la historia es contada por los medios de comunicación, y la tarea de generar experiencias comunitarias está siendo más que difícil. Estamos frente a un cambio de época y de civilización. Estamos ante la gestión de nuevos discursos globalizadores y de nuevos referentes simbólicos.

Ello nos obliga a deconstruir las categorías anteriores, reconstruir y reinventar relaciones sociales y con ellas, está la deconstrucción, reconstrucción y reinvención de las identidades. 


\section{Un ejemplo de fin de siglo y de milenio}

Después de la guerra fría, el paradigma de análisis de la realidad política internacional fue el mundo bipolar. Después de la caída del muro de Berlín ya nada fue igual. Sin embargo, a muchos se nos olvidó que desde hacía cientos de años había un mundo olvidado por todos: el mundo indígena que constituye la realidad de una buena parte de los países subdesarrollados y de la mayoría de los pueblos de América Latina.

Ese mundo olvidado resurgió hacia finales del siglo XX y se hizo presente, entre otras cosas, gracias a los medios de comunicación.

A pocos, o no a muchos, se les había ocurrido que la globalidad estaba dejando fuera a los de siempre, a los desamparados, a los desprotegidos, a los pobres, a los indígenas.

Ellos nunca fueron concebidos como parte de la modernidad, ni siquiera como prioridad dentro de las políticas públicas diseñadas por los Estados nacionales. Pese a ser sustento básico de la identidad nacional de los pueblos en los que se encuentran asentadas, dichas comunidades perdieron se perdieron completamente en el olvido (Bonfil Batalla, 1990: 161-186).

En su gran mayoría, estas comunidades han sido víctimas de la colonización, desarticuladas por los gobiernos independientes y marginadas por los gobiernos revolucionarios. Sus demandas nunca han sido tomadas en cuenta y mucho menos ahora, cuando la propia estructura de constitutiva fundamental de los Estados-nación se tambalea debido a los impactos atestados por la globalidad.

Un ejemplo muy claro de esta cuestión está en México. El 1 de enero de 1994, justamente el día previsto en que México entraba a formar parte del bloque económico de América del Norte, gracias a la entrada en vigor del $T^{T} C^{4}$ el Ejército Zapatista de Liberación Nacional, compuesto por unos cuantos cientos de indígenas pertenecientes a comunidades asentadas en la selva chiapaneca, le declara la guerra al Estado mexicano, reclamando justicia. ${ }^{5}$

La declaración de guerra sorprendió a propios y extraños, principalmente porque era una muestra de que la función social del Estado mexicano había sido sobrepasada. Ningún elemento de inteligencia o de seguridad nacional había informado oportunamente a las autoridades de que la declaración de guerra estaba en puerta. Se sabía de la existencia de grupos guerrilleros en la zona, pero el gobierno mexicano confiaba plenamente en su capacidad de represión y nunca pensó que un pequeño grupo, con la cobertura mediática

4. Tratado de Libre Comercio de América del Norte.

5. La declaración de guerra del EZLN se llevó a cabo el 1 de enero de 1994 en San Cristóbal de las Casas, Chiapas en México. 
apropiada, haría presa de los titulares de los principales periódicos y noticieros electrónicos del mundo. De la noche a la mañana, el Ejército Zapatista de Liberación Nacional se convirtió en el símbolo reivindicativo de los grupos marginados del tercer mundo y de las injusticias de la economía del libre mercado y de la globalidad.

Es en ese sentido, que el movimiento zapatista se convierte también en un ejemplo representativo de las formas de resistencia que se dan en el mundo occidental, que son parte de los conflictos inherentes a la globalidad y en las próximas páginas me permitiré explicar el porqué.

La situación hubiese pasado completamente desapercibida en otros tiempos, y con otros esquemas de operación, como en el pasado, cuando el Estado nacional mexicano disponía de libertad plena para reprimir la sedición y el levantamiento armado; pero no en la era de la globalidad y de los derechos humanos, en que la mayoría de los habitantes del planeta pueden ser testigos de lo que está sucediendo en cualquier parte del mundo, gracias a los medios de comunicación.

El problema rápidamente escaló a niveles internacionales, consiguiendo la atención de la opinión pública internacional y poniendo en la mira de propios y extraños las paradojas de la globalidad y las injusticias del libre mercado.

Unos cuantos indígenas sin mucho apoyo militar y por supuesto en condiciones de resistencia, pusieron en juego la política interna y el manejo de la seguridad nacional del Estado mexicano.

Lo anterior habla de los nuevos procesos globales de control social, la economía de libre mercado, el flujo libre de información y la escalada de los problemas no resueltos domésticamente, pero presentados a nivel global rebasan las capacidades de los Estados nacionales. Como dice Ulrich Beck ¿quién puede establecer las normas para los Estados-nación cuando sobrepasan sus procesos políticos? y continúa diciendo:

Crisis ecológicas, migración y xenofobia, crimen, flujos financieros, evasión de impuestos, desempleo, pobreza y justicia, el futuro del Estado social, retiros y pensiones, son todos problemas globales, y no sólo en el sentido de ser terrestres, es decir, atañen a cualquier localidad, ciudad o grupo. Hay pues una nueva dialéctica de lo global y lo local que no es fácil de acomodar en la política nacional (Beck, 2001: 67).

Las pruebas están por todos lados: industrias anteriormente ampliamente reguladas y controladas por los Estados nacionales, son ahora las primeras promotoras de los mercados globales: telecomunicaciones, medios de comunicación, industria del entretenimiento, alimentos, finanzas, y otras más que 
resultan ser vitales para los indicadores básicos del desarrollo están ahora dentro del flujo global.

Los nuevos estándares están trastocados: desde la forma de entender el crecimiento, el desarrollo, la pobreza, el trabajo y el mercado, pasando por cuestiones de educación, salud, y por supuesto de identidad.

El nuevo cosmopolitismo global está siendo dictado por la racionalidad occidental que abrazó la tecnología como instrumento del desarrollo, generando los modelos y los nuevos patrones de relación y de aprendizaje.

Los Estados nación se están tornando incapaces para regular los grandes movimientos internacionales, pero en el ámbito internacional no hay forma todavía de establecer patrones de ingerencia sin incurrir en el problema de la soberanía nacional.

Al nivel de las identidades, los ciudadanos del mundo ahora se preguntan en dónde están los controles y cuáles son los referentes, cuáles los nuevos modelos a seguir. ¿Cuáles son los valores culturales que estarían siendo promovidos y cuáles estarían siendo subsumidos?

En términos generales el panorama que prevalece es el de la hegemonía simbólica, en donde la información estereotipada suministrada por los medios de comunicación y los valores promovidos por éstos amplía la brecha entre la característica de los grupos y su conocimiento del otro. Como fuentes de información, los medios de comunicación juegan un papel importante en la integración de percepciones sobre las culturas que no se conocen, de tal suerte que la experiencia cultural o intercultural directa es sustituida por referentes indirectos provenientes de periódicos, libros, revistas, radio o televisión (Fishbein y Ajzen, 1975: 173 y Coatsworth y Rico, 1989: 117-118). ${ }^{6}$

Nuevamente, la paradoja increíble es pensar que en un mundo interconectando, con la posibilidad real de establecer contactos con otros, se estén presentando formas de descontextualización de la realidad cultural ajena, y se generen mecanismos de alejamiento.

La interculturalidad es vivida de manera vicaria, pero no de manera directa. Los medios de comunicación lejos de propiciar la vivencia directa, están obligando al repliegue y a la defensa de la identidad cultural amenazada. El riesgo de la segregación es mayor en tanto los componentes de la desigualdad se aceleren y el recurso por el que se compita sea finito, y en ese sentido el mundo occidental moderno está llevando los excesos en la desigualdad a un abismo peligroso.

6. Fishbein y Azjen y Coatsworth y Rico hablan alternadamente del papel de los medios de comunicación como vehículos alternativos de experiencia y de obtención de información. Ver por ejemplo: Fishbein y Azjen. Belief, attitude, intention and behavior: An introduction to theory and research. Addison-Wesley Publishing Co., 1975. pp. 133. y Coatsworth y Rico. Imágenes de México en Estados Unidos. Fondo de Cultura Económica, 1989. pp. 117-118. 
Beck pronostica que los desacuerdos serán mayores entre mayores sean los contrastes entre tradiciones culturales (Beck, 2001: 69-70).

Ahora bien, no se trata aquí de proponer nuevamente el "Choque de Civilizaciones" a la manera de Huntington (1996), pero sí de establecer las condiciones de relación que inciden directamente en la afirmación o no afirmación de la identidad de los sujetos sociales.

La lucha por la política es entonces una lucha también por la ética y por la subsistencia, por la defensa de la identidad cultural, y la presencia de los medios de comunicación es el nuevo catalizador de los procesos. "Al lado de la tolerancia y el disfrute de la diversidad crecen la exclusión y la xenofobia (Beck, 2001: 71), lo cual habla de la cualidad multiétnica de la sociedad global y de la necesidad de la recomposición de los fenómenos de referencia. Ello implica la necesidad de la reconstrucción de los Estados; implica la revaloración de las nuevas estructuras sociales; obliga a la reivindicación de las identidades; reconoce nuevas necesidades en los sujetos e implica el análisis de las nuevas estructuras sociales en gestación.

Los medios se están convirtiendo en las nuevas arenas públicas trasnacionales que están llevando a la discusión los asuntos globales, pero también las discusiones locales.

En la era de la globalidad, aún una minoría débil o perseguida tendría voz y legitimidad gracias a la atención de los medios masivos. Conectarse a Internet no genera de suyo ciudadanos globales, pero sí pone en contacto a sujetos con realidades diversas, como bien lo demostró el EZLN en Chiapas, México el 1 de enero de 1994.

Ahora bien, no cabe duda que el conflicto indígena y el caso de Chiapas está siendo analizado en diversas partes del mundo porque es un ejemplo de la recomposición de imaginarios vigentes a fin de siglo, pero también de la evidencia de las desigualdades que son evidentes aún frente a los marcos de la globalidad. Para algunos estudiosos, como Cornelius Castoriadis, en Chiapas se conjugaron de manera evidente numerosos símbolos mundiales creados de manera imaginaria en los últimos años: el símbolo cultural étnico que resurge de la muerte y el olvido; la afirmación de la mujer negada como símbolo de emergencia; la participación de la sociedad civil —no sólo mexicana sino amplia e internacionalizada - que normalmente se organiza en torno a problemas públicos (Castoriadis, 2001, 13), lo cual permitió abrir de nuevo la polémica en torno a la discusión y la participación de los sectores sociales relegados. Castoriadis mismo reconoce que si bien el futuro de la política en la era de la globalidad deberá estar basado en una participación amplia, la pregunta básica sigue siendo la forma de crear de condiciones de mayor equidad a pesar de la desigualdad.

Por otra parte, la participación tiene una serie de vías, pero también una serie de aristas: el hecho de que las nuevas tecnologías y los medios de 
comunicación en particular hayan hecho visible el conflicto chiapaneco, no necesariamente ha promovido la participación ciudadana, sino que ha logrado una sociedad de espectadores televisivos, víctimas de un fuerte letargo que no de ciudadanos activos.

La coexistencia plural de modos de ver y de interpretar la realidad ha sido entonces en gran medida producto de los distintos vehículos de transmisión de significaciones, $y$ en este sentido los medios de comunicación han funcionado como aglutinadores de estos referentes simbólicos con otros como el concepto de identidad y de nación.

El mundo que se presenta ante nosotros, como diría Castoriadis, está indisolublemente tejido a lo simbólico, aunque no se agote en ello. La realidad como la conocemos está pues atada a una red simbólica dentro de la cual se ubican los grupos y las instituciones. La realidad como la conocemos está pues atada a una red simbólica dentro de la cual se ubican los grupos y las instituciones. De tal suerte que para hablar de la identidad mexicana a fin de siglo y de milenio, es importante hablar de un pueblo que arrastra la construcción de su identidad desde el principio de los días.

\section{Los antecedentes de una identidad amenazada}

El primero de enero de 1994 será recordado como un parteaguas en la historia reciente de México; acontecimientos registrados prácticamente en cascada a partir de esa fecha, han venido a suscitar una profunda huella en nuestro país. México no volvió a ser el mismo desde entonces: súbitos movimientos de reemergencia y reacomodo de fuerzas a nivel social y político han venido a trastocar no solamente las estructuras políticas y traído como consecuencia la emergencia de nuevos actores sociales, sino también a acelerar procesos de recomposición de la identidad. Y es que el reacomodo de fuerzas ha sido tal, que los procesos de apropiación del cambio y de la transformación se han acompañado-por un lado, de la emergencia de nuevas propuestas de nación, pero también - por otro-de movimientos importantes de resistencia cultural. Así, las transformaciones vividas orillan a nuestro país a incorporarse a un entorno que le exige condiciones de participación distintas (Casas, 1996: 71-72).

Hoy en México amanecemos a un crisol democrático y experimentamos por vez primera la apertura irrestricta a la información, o al menos ese es el nuevo imaginario social que comparten gran parte de los mexicanos; pero la situación no siempre fue ésa.

La rebelión de Chiapas fue el resultado, entre otras cosas, del anquilosamiento del sistema político mexicano, de una falta de información que impidió el procesamiento oportuno de las demandas sociales. Demandas que se estan- 
caron durante decenas de años, y que resurgieron en un momento crucial para nuestro país: el momento en el que según el discurso del gobierno en turno, nos acercábamos al Primer Mundo. México estaba a punto de entrar a formar parte del bloque económico más importante de América del Norte, y aunque la rebelión zapatista no frenó nuestro ingreso al Tratado de Libre Comercio de América del Norte, sí puso en evidencia la enorme fragilidad política y económica de nuestro país.

Los acontecimientos verificados durante los años de 1993 a 1995 sentaron las bases para el resquebrajamiento definitivo del régimen priísta y para el cambio político que experimentó el país en julio del 2000 cuando por primera vez en su historia los mexicanos eligieron a un presidente de otro partido político.

Ya hemos dicho aquí que parte de la visibilidad que ganó el Ejército Zapatista de Liberación Nacional se debió a la amplia difusión internacional que el movimiento logró a través de distintos medios, no solamente nacionales, sino principalmente internacionales y sobre todo a través del Internet. El gobierno del presidente Fox, electo para gobernar a partir del 1 de diciembre del año 2000 eligió jugar el mismo juego mediático que el zapatismo y rápidamente estructuró una ofensiva mediática dedicada a mostrar su disposición para el diálogo y para llegar a acuerdos de paz.

La cuestión mediática ha puesto sobre la agenda nacional e internacional nuevamente el indigenismo. Si bien los gobiernos priístas tardaron un buen número de años en sepultar en el olvido a los pueblos indígenas y promover la idea de un México revolucionario y moderno, en unas cuantas semanas el mundo se percató de las carencias de los pueblos indios, y el factor de la identidad se puso de nuevo en la mesa de las discusiones.

La cuestión indígena puso en juego muchas cosas, no solamente el proyecto nacional, sino también los peligros de la globalización. La identidad de los verdaderos mexicanos se vio amenazada por el México moderno, y de cara al siglo XXI, el sistema político mexicano se tuvo que enfrentar al viejo dilema de siempre, gobernar en la desigualdad.

El cambio democrático también enfrentó al país a otras discusiones sobre la identidad. Durante años, los medios de comunicación se empeñaron en mostrar una imagen uniforme de México: un México que se movía de manera lenta pero segura hacia el desarrollo. De pronto, las realidades fueron otras. La apertura en la información que se sobrevino a la caída del régimen priísta destapó una realidad que pocos mexicanos querían ver: pobreza, marginación, delincuencia e intolerancia.

La alternancia en el poder trajo también como consecuencia una variedad de opiniones, una nueva relación entre los medios de comunicación y el poder político, y problemas en los distintos imaginarios de país que se presentaban ante la sociedad. 
Los medios de comunicación, encandilados frente a la posibilidad de una apertura irrestricta de información, dieron rienda suelta a un desempeño abierto pero en ocasiones poco ético. Los ciudadanos, lejos de ser considerados como tales, y dentro del propio marco de la comercialización de la información comenzaron a ser tratados como consumidores. La pluralidad como posibilidad de expresión de opiniones diversas fue abandonada a los excesos, de manera que muy pronto, los ciudadanos nos vimos inundados de visiones distintas de nuestro país que comenzaron a conformar una visión esquizofrénica de nuestra propia identidad.

En México por tanto, en los últimos años nos hemos visto sometidos a un doble proceso de construcción y deconstrucción de nuestra identidad. En primer término porque durante buena parte de nuestra historia, las instituciones, entre las que se encontraron la familia, la iglesia, la escuela y los medios de comunicación, se encargaron de construirnos una identidad nacional que permitiera la cohesión nacional y la operación del aparato estatal; y en un segundo momento, en el que debido al quiebre del sistema político y de su relación con los medios de comunicación, se vino abajo esa construcción imaginaria de la identidad, lo cual nos obligó a deconstruir sus elementos y tratar de generar nuevas identidades sobre la base de otros.

El reconocimiento del otro, como alguien no diferenciado, muy distinto al imaginario moderno al que las clases medias y altas aspiran para este país nos remite a una recomposición de la cultura.

Nuestros sistemas culturales han sido obligados, en cuestión de unos cuantos años a recomponerse: por un lado han sido obligados a ejecutar un cambio de ritmo para entrar en una temporalidad diferente: la que marca la globalidad, la que marcan los ritmos de la economía del mercado, y por otro, a reconocer en su historia nuestras raíces y nuestros orígenes milenarios. Ese fue el cuestionamiento de Chiapas, por eso los tiempos del movimiento zapatista nunca coincidirán con los del gobierno. El gobierno mexicano necesita apurarse a lograr la paz porque así lo marcan los tiempos de los mercados y de la comunidad internacional. El gobierno foxista se apresura a demostrar que tiene el control del país para lograr el apoyo de la comunidad y de los organismos internacionales; sin embargo, los indígenas de México insisten en demostrar que sus tiempos son otros y que los mexicanos tienen otras aspiraciones, otras demandas que van mucho más allá de su incursión en la economía de mercado y que tienen que ver con demandas universales por la justicia y la equidad. La globalidad misma y todos sus universalismos y estandarizaciones están en juego. Los mexicanos nos vemos por tanto enfrentados a una identidad múltiple.

Las propias nociones de convivencia armónica, de tolerancia, de madurez política se ponen sobre la mesa de la discusión, pero poco podemos hacer para 
estrechar el tejido social si no podemos ni siquiera reconocernos a nosotros mismos.

El pasado, nuestra memoria histórica, nuestros valores y nuestras costumbres tienen que ser reconceptualizados con el fin de proponernos un presente. Debemos deconstruir para volver a construir imaginarios mucho más incluyentes de la diversidad, y aunque parezca contradictorio, que también reconozcan la existencia de la globalidad.

$\mathrm{El}$ proceso de deconstrucción debe ser obtenido por la vía de la oposición conceptual entre identidad y resistencia cultural. Debemos analizar cuáles son las alternativas de la diversidad frente a la homogeneización que reclama un mundo globalizado; por lo tanto, es necesario hacer una revisión de realidades que coexisten.

El naciọnalismo en sus diferentes vertientes, es una más de las manifestaciones de los autoritarismos políticos, y como tal resulta anacrónico frente a una realidad que clama por la participación democrática. La identidad nacional pues debe ser revisada para incluir a otros grupos, a otras expresiones políticas y culturales. Es pertinente reconocer que así como el nacionalismo se enfrenta a las exigencias de la modernidad, la identidad nacional se opone a la resistencia cultural, considerada ésta última como el movimiento de oposición ante procesos de transformación social implementados desde la cúspide... La resistencia cultural es el signo más reciente de reclamo hacia las promesas incumplidas de la modernidad, hacia las arbitrariedades del centralismo político que inhibe el desarrollo autónomo de las estructuras sociales y hacia los procesos no completados de democratización (Casas, 1996: 75).

El movimiento de liberación indígena representado por la insurrección zapatista representa justamente un movimiento de resistencia cultural reivindicador de las promesas incumplidas de la modernidad, pero sobre todo de rechazo ante las arbitrariedades del centralismo político. En este sentido, era de suponerse que al entrar México en una fase de desarrollo democrático y con la llegada al poder de un partido político distinto al PRI se pensara en el abandono de las viejas prácticas políticas represivas de los antiguos gobiernos revolucionarios. Sin embargo, el movimiento indígena demostró, que la resistencia milenaria hacia la marginación no se borra de un plumazo, ni aún cuando éste sea el que cristaliza en el voto, ya que las viejas prácticas de relación entre las estructuras sociales implican mucho más que una campaña electoral que sustituye a un presidente por otro o a un partido por otro.

De hecho, el movimiento zapatista obligó a una recomposición aún más importante de la identidad nacional mexicana, no solamente aquella que se relaciona con la otra cara de los mexicanos, misma que fue difundida ampliamente a través de los medios de comunicación, sino también con la necesidad de descomponer y volver a estructurar las viejas identidades políticas del Presidente y de lo que significa ser partido gobernante y partido de oposición. 
En este caso, ambas estructuras se cimbraron; es decir, desde la estructura nacional política, desde donde originariamente se venía construyendo la idea de la nación a partir de una institución monolítica estatal compuesta por el PRI (partido en el poder) y el Estado como entidad política, hasta la estructura cultural de la base, ya que el choque del zapatismo y la inclusión de los grupos indígenas marginados a la esfera de lo cotidiano, vino a cambiar todas las nociones preconcebidas de lo que venía a constituir la urdimbre constitutiva de lo mexicano.

A los indígenas los habíamos visto en nuestros viajes turísticos, como viejos rezagos del México prehispánico, vendiendo artesanías afuera de los centros arqueológicos o pidiendo limosna en las grandes metrópolis, pero nunca los habíamos visto capaces de insertarse en la modernidad, ${ }^{7}$ haciendo declaraciones a la prensa, interactuando con los medios electrónicos, manejando un celular y un radiolocalizador, utilizando el Internet para llevar al ciberespacio su propuesta y sin embargo, oponiéndose de frente al paradigma modernizador global.

Es un hecho que en otro contexto dichos panoramas hubiesen sido totalmente imposibles, sin embargo, el momento fue propicio y los elementos de articulación se dieron de forma tal que ambas instituciones se vieron enfrentadas una a la otra exigiendo al otro el respeto irrestricto por una visión de país.

Por un lado, el Estado nacional, anteriormente monolítico e infranqueable, ahora fracturado e irremediablemente abriendo los espacios para la participación; por otro, los grupos indígenas, resistiendo, pero transformando con su sola presencia la realidad nacional. Una verdadera muestra de procesos de construcción y deconstrucción de las identidades, en donde la nación misma fue el objeto principal de la discusión, y en donde la tecnología y los medios de comunicación fueron testigos y actores y seguramente también aceleradores del proceso.

Después de siglos de resistencia pacífica, los indígenas alzaron su voz a través del Ejército Zapatista de Liberación Nacional y se declararon grupo armado. A siete años de su pronunciamiento, el EZLN salió de Chiapas y en su marcha hacia la capital de la República Mexicana dio su palabra. El nuevo gobierno de Vicente Fox hizo lo suyo: Aseguró una y otra vez que lo más importante para su gobierno era el diálogo y que estaba dispuesto a reunirse él o representantes directos de su gobierno, con quien hubiese que reunirse.

7. García Canclini diría que este es un claro ejemplo de la hibridización de las culturas y de las formas que utilizan los pueblos indígenas para entrar y salir de la modernidad. Ver: García Canclini, Néstor. Culturas híbridas. Estrategias para entrar y salir de la modernidad. CNCA-Grijalbo, 1990. 
Fue ese un auténtico ejercicio de comunicación fallida. Las declaraciones de ambas partes parecían amplios monólogos. Cada uno tachaba al otro de no querer la paz.

Los representantes del EZLN insistían en querer hablar ante la máxima tribuna de la nación. Las fuerzas reaccionarias se oponían. Después de arduas negociaciones se les permitió hacer un pronunciamiento ante el Congreso de la Unión. Los medios fueron testigos.

El 28 de marzo del año 2001 se enfrentaron cara a cara dos Méxicos. El México indígena y el México moderno. Cuatro de los once canales de televisión abierta visibles en la Ciudad de México transmitieron durante más de cinco horas la histórica reunión en el Palacio de San Lázaro sede del Poder Legislativo. La reunión también fue transmitida en vivo vía Internet.

Los grupos indígenas hablaron:

Hoy queremos darles a saber, ante esta Cámara de Diputados y Senadores y ante el pueblo de México y el mundo, que cuando se acaben las mesas que faltan de democracia y justicia, la de bienestar y desarrollo, la mesa especial de derechos de la mujer y se cumpla lo que acordamos en estas mesas que faltan, nosotros decimos que ahí se acaba el diálogo porque resuelve las causas que empezaron en 1994 (Comandanta Esther. Ejército Zapatista de Liberación Nacional).

Las inequidades estaban claras sobre la mesa, lo que no estaba tan claro era la forma de resolver esas desigualdades. Por más que el gobierno insistiera en construir hospitales y escuelas, no era eso lo que los indígenas querían. Lo que querían era el reconocimiento a los derechos indígenas y, más allá del reclamo a la inserción de México a la globalidad, estaba su propia inserción a un proyecto de nación.

El Palacio Legislativo parecía una auténtica torre de Babel. No solamente hablaron más de veinticinco voces en diferentes lenguas indígenas durante más de cinco horas, sino que entre propios y extraños, aun compartiendo el español era evidente la posibilidad de entendimiento.

Desde el punto de vista de la nueva y modernamente adoptada mentalidad occidental, los legisladores se debatían entre la forma de asignar nuevos significados a palabras como soberanía y autonomía. Sentían resquebrajarse la propia definición del Estado de derecho al tener que admitir la posibilidad de pueblos distintos agrupados bajo una noción de identidad política única. La multiculturalidad simplemente no era compatible después de haber pugnado históricamente por la unicidad de la identidad nacional.

México se debatía ante una realidad, que además estaba siendo vista por los ojos del mundo. Somos un pueblo con carencias, pero ésas pueden ser resueltas. Lo que es más grave es que somos un pueblo que no se conoce a sí 
mismo, no sabe quién es. No sabe que durante siglos ha convivido con otros que tienen muy claro lo que son y lo que quieren ser:

Los pueblos indígenas queremos vivir con nuestra lengua, con nuestro color, con nuestra agua, con nuestro río y nuestra montaña, con nuestro vestido, con nuestra cosmovisión, así como somos.

No queremos dejar de ser mexicanos sino ser parte importante del fortalecimiento del país, nunca hemos querido poner en peligro su unidad y soberanía, al contrario, hemos sido defensores de nuestra Patria y lo seguiremos siendo (Adelfo Regino. Representante del Consejo Nacional Indígena).

La televisión y los medios gráficos mostraban un mosaico multicolor y esquizofrénico de iconografía nacionalista. Por un lado, la vestimenta típica de los comandantes indígenas hablando en el podium de la más alta tribuna del país, los pasamontañas y el protocolo legislativo, por otro la bandera nacional, y al final de la alocución indígena, un sonoro "iCon los pueblos indios, viva México!" seguido por el Himno Nacional.

Si el mundo entero estaba observando el proceso, se habrá percatado de que sólo en México es posible la coexistencia de mundos aparentemente irreconciliables. A nivel global, nuestro país dio cuenta de lo que significa tener en su seno un conflicto local cuyas reivindicaciones son universales. ¿Qué más prueba puede haber de que lo global y lo local coexisten?

¿Qué evidencia más plena puede haber de la necesidad de la deconstrucción y reconstrucción de lo nacional y de lo identitario?

Términos como soberanía, autonomía, gobierno, nación, país, etc., fueron súbitamente puestos en duda. Su cuestionamiento fue tal que probablemente en la jerga política de nuestro país, y quizás de otras latitudes se comience a hablar más en términos de reconocimiento y colectividades.

Lo que pudimos articular fue la presencia de un auténtico movimiento de transformación para el cambio. El Estado nacional cambió para permanecer y la figura de la identidad nacional hubo de recomponerse, obligada por las exigencias de una cultura milenaria, que pugnaba por redefinirla. Una cultura que es la auténtica fuerza transformadora de la sociedad, y que por lo tanto, es cambiante, que articula los verdaderos procesos de transformación y de cambio y que se opone los designios verticales del Estado, constituyéndose en auténtico mecanismo de resistencia cultural (Casas, 1996: 76).

La marcha y la presencia zapatista trajo a la mesa no solamente una serie de demandas no resueltas, evidencias de largos siglos de marginación de un proyecto político nacional, sino que también por sobre la política puso sobre la balanza los verdaderos mecanismos articuladores de la identidad nacional mexicana: cultura y comercio. A partir de los años veinte el nacionalismo mexicano se sustentó sobre la base de la cultura nacional, el mestizajc, la 
lengua, la historia, el culto a la historia de bronce. A partir de los años ochenta, el proyecto de país, junto con su correlato identitario nacional se ligaron irremediablemente a la economía y a las leyes del mercado. La identidad nacional mexicana se haría fuerte en la medida en que su economía fuese fuerte también, con posibilidades de ser reconocida a nivel internacional por su capacidad de comercio. La identidad nacional mexicana pues se ligó a los parámetros del mercado global. Ambas identidades se colapsaron frente a una realidad evidente: sectores marginados, sectores emergentes, inequidad en la distribución de la riqueza, abismos en la educación, demandas de salud, demandas de vivienda, desempleo, una juventud desorientada, falta de seguridad social e inestabilidad política. Ya en 1996 decíamos:

La identidad nacional está por agotarse. El sistema está perdiendo su capacidad de utilización del nacionalismo en su vinculación con el orden político. Los mexicanos hemos aprendido que, aunque no aparezca en los libros de historia, en el México del siglo Xx se ha librado más de una revolución.

Así, el manipuleo de la identidad nacional puede ser una de las riendas que el sistema estaba acostumbrado a jalar, la otra era la economía -a ambas da la impresión de que las había soltado por completo-; ahora intenta retomarlas. Sin embargo, esa vuelta al orden y a la estabilidad se apoya sobre bases falsas, ya que desatiende al sustrato cultural.

La atención de las expresiones sociales y culturales debe ser la prioridad auténtica; todo lo demás puede volver a la estabilidad temporal, pero puede resultar más costoso a largo plazo. Una auténtica expresión cultural plural es en realidad su única alternativa, de otra manera lo que ahora puede aparecer como resistencia cultural, bien puede convertirse, como lo demostró Chiapas, en resistencia política (Casas, 1996: 83).

Hoy en día podemos asegurar que frente a nuestros ojos se están dando procesos de transformación irreversibles. El reconocimiento y la presencia de grupos anteriormente marginados de los proyectos nacionales, que entre otras cosas teniendo a la tecnología y a los medios de comunicación como testigos, están logrando abrirse un espacio a la participación política, pero no sobre la base de las estructuras establecidas por el sistema, sino de manera paralela, subvirtiendo esquemas, alterando las reglas y logrando su inserción en el imaginario político y social de la ciudadanía.

Si el 2 de julio del año 2000 México se insertó en el grupo de países capaces de llevar a cabo procesos electorales auténticamente democráticos, la democracia todavía no se ha instaurado. Hace falta todavía aprender a ser incluyentes en la construcción del proyecto de nación que queremos para este siglo. Los grupos indígenas demostraron que podían hacer la revolución, pero no una revolución armada, sino una revolución ideológica asistida por la tecnología. 
Nos aventuramos a conocer las ventajas de las nuevas tecnologías sin por ello despreciar el valor de la comunicación cara a cara. Nos presentamos ante el mundo con una identidad nueva, pero la misma, distinta pero arraigada, homogénea pero heterogénea.

La vida y el despliegue de las naciones son siempre procesos específicos. El problema es determinar en qué momento de la nación se están desplegando qué tipo de vidas y sobre todo poder especificar hacia dónde conducen sus destinos (Béjar, 1999: 184).

Cuando en un momento determinado en la vida de una sociedad, se empiezan a desplegar procesos que no existían anteriormente, es momento de preguntarse si no se daban porque no existían los mecanismos para ello, porque el contexto es diferente, o si esos procesos están siendo visibles porque aparecen nuevos mecanismos que permiten que en este momento se pongan de manifiesto.

Estamos frente a sociedades que comienzan a manifestar procesos y comportamientos que nunca antes habían desplegado. ¿Son esos procesos consecuencia de los movimientos de globalización que sufre el planeta entero? ¿Son parte del fin de siglo y del fin de milenio? ¿Corresponden dichos procesos de cambio a un punto natural en la evolución de dichas sociedades? ¿O están siendo detonados por los mecanismos de difusión de información de los que disponemos hoy en día, llámese nuevas tecnologías de comunicación?

Nuestra propuesta es que no existe una causa única de las transformaciones en la conformación de identidades, pero sí existen tendencias más o menos previsibles hacia donde se dirigirán dichos procesos.

Coincidimos con Margulis en el sentido de que existen en cada sociedad códigos culturales superpuestos, tramas de sentido que tienen diferente alcance espacial, que están en constante cambio y transformación, sumidas en procesos de cambio y en luchas por la constitución e imposición de sentidos, que se arraigan en la dinámica social (Margulis, 1997: 41-42).

En última instancia, la dinámica social es la que está definiendo esa imposición de sentidos, y en la lógica de la globalización, ese sentido está dado por el eje económico. Eres en la medida en que contribuyes y en la medida en que consumes. Por eso los patrones y conceptos anteriores que vinculaban a las identidades con utopías nacionalistas ya no tienen ningún arraigo en el mundo de la globalidad.

Mientras que el Estado-nación se anclaba a los referentes físicos de lengua, raza y territorio, la globalidad, en sí misma es desterritorializante. La nueva ideología del todo interconectado se libera de las identidades locales, neutralizándolas o destruyéndolas para generar en el horizonte la posibilidad de estructurar identidades trasnacionales, no sólo de género o de clase, sino también de consumo. 
Como macro categoría de trabajo la globalidad - pese a su carácter inclusivono puede abarcarlo todo. Existen fenómenos sociales que se dan fuera de la globalidad, como las fragmentaciones y las exclusiones de lo global; o bien, existen áreas de trabajo y de estudio que tienen que ser dejadas de lado porque no entran dentro del proceso de globalización analizado; así la globalidad puede ser económica provocando fenómenos de dispersión homogénea de la distribución de los bienes, pero puede interactuar en distintos niveles con lo político y con lo social, generando exclusiones y asimetría (Casas, 1998: 32).

Dichas exclusiones y dicha asimetría han generado todo tipo de movimientos a nivel regional y local. Las manifestaciones de lo global son, sin embargo, independientes de las manifestaciones de lo local, y muchas veces se le oponen.

La globalidad tiende a proponer patrones estandarizados de conducta, las manifestaciones de lo local se le oponen y buscan la diferencia. La globalidad establece a la economía el eje de los procesos olvidando que, de suyo la cultura es la urdimbre que articula a de los conglomerados sociales.

La identidad y la generación de identidades constituyen un movimiento circular que reconoce esencialmente la diferencia.

En todo el mundo se registran movimientos sociales y políticos que denuncian la exclusión de los grupos marginados. Dichos grupos hacen énfasis en la necesidad de rescatar su identidad y denuncian los movimientos de exterminación de los Estados-nación o de integración a costa de la diversidad cultural.

Frente a la globalidad las identidades se desdibujan, pero ante la posibilidad de la exclusión o la exterminación definitiva, las identidades se robustecen.

\section{De la globalidad o la era de la reivindicación de las identidades comunitarias}

Hasta aquí podemos visualizar ciertas tendencias genéricas en los movimientos de reestructuración de las identidades, que cruzan las fronteras de lo individual y se acercan a la conformación de nuevas identidades colectivas que existen ahora en la sociedad de la información. Dichas tendencias son las siguientes:

1. Un movimiento acelerado hacia la desterritorialización. Los sujetos estarán cada vez menos vinculados a países o a territorios y más vinculados entre sí como sujetos individuales. Esto hará prácticamente inviable el modelo de Estado-nación que conocemos y obligará a la gestación de otro tipo de 
constructos sociales y políticos más vinculados posiblemente con la nueva Nación Digital.

2. Un desfasamiento entre las identidades personales y las identidades colectivas. Los individuos tendrán que acostumbrarse a viajar entre las identidades personales y las identidades colectivas en la red, teniendo que alternar permanentemente entre sus personalidades reales y sus personalidades virtuales tanto en el mundo físico como en el mundo electrónico. En el ciberespacio estarán en posibilidades de crear identidades colectivas de una manera más simple y menos comprometida que en el mundo real.

3. Un movimiento permanente de recomposición de los grandes textos de comunicación que circularán en las redes. Como, de acuerdo con Fukuyama, el siglo XX vio el fin de la historia y el fin de todas las ideologías, en el siglo XXI será menester crear las nuevas ideologías. Estas se gestarán a partir de grandes bloques de conocimiento simbólico que circularán en la red y que eventualmente se convertirán en los grandes textos de integración entre las comunidades virtuales. No hay nuevos líderes ni nuevos ideólogos; por lo pronto el vínculo está en la tecnología de redes, pero eventualmente aparecerán los nuevos gurús que habrán de generar los megatextos que aglutinarán los códigos del ciberespacio y generarán las nuevas confrontaciones de pensamiento.

4. Por último, la gran cultura mediática y la nueva sociedad de la información traerá como consecuencia individuos mucho más acostumbrados a la búsqueda de datos, a la participación y a la retroalimentación. Ello tendrá consecuencias en el mundo físico real, que serán palpables, ya que los antiguos ciudadanos del mundo estaban acostumbrados a la censura por parte de los centros ideológicos y del poder. Al generar una nueva cultura cibernética acostumbrada a la búsqueda irrestricta de información, y al estar toda la información circulando libremente, los sujetos individuales se acostumbrarán cada vez más a la participación. En un primer momento, ello hará prácticamente imposible el retorno a los sistemas autocráticos en los cuales la información es controlada. Individuos mucho más participativos y más demandantes provocarán nuevas formas de comunicación más interactivas y más dinámicas; sin embargo, en un segundo momento, en la misma sociedad de la información comenzarán a aparecer candados que volverán a gestar centros de poder, con la diferencia de que éstos no podrán ser tan claramente identificados en el mundo cibernético como podían haberlo sido en el mundo real.

En la sociedad de la información no todo lo que brilla es oro. No toda la información es verdadera, ni toda la información es confiable. Se gestará la idea de que todo está en la red, pero los nuevos centros de poder se cuidarán bien de distribuir información de distintas categorías y para distintos usos. 
Lo anterior pudiera anticipar la gestación de una nueva dictadura electrónica. La posibilidad existe. En el momento de nacer, toda tecnología ha sido controlada por aquel de los poderes que ve amenazada su primacía.

Los grandes barones de la tecnología computacional y de las telecomunicaciones, por un lado buscan la difusión de su cultura tecnológica, pero por otro lado, saben que en la propia cultura tecnológica podría radicar el germen de su destrucción. Para ellos, la estrategia es hacer del recurso un recurso indispensable para poder controlarlo a través de la dependencia de uso. Para nosotros, es revisar permanentemente el proceso, reflexionar sobre él y desarrollar habilidades que nos permitan navegar a contrapelo en movimientos de contracultura.

\section{Referencias bibliográficas}

Albrow, Martin (1996). The Global Age. Stanford University Press.

Beck, Ulrich (2001) "Democracia global” en Metapolítica.Vol. 5 abril-junio. Béjar, Raúl y Héctor Rosales (Coordinadores) (1999). La identidad nacional mexicana como problema político y cultural. Colección Umbrales de México. Cultura y Sociedad. México, Siglo XXI Editores, Universidad Nacional Autónoma de México, Centro de Investigaciones Multidisciplinarias en Ciencias y Humanidades.

Bonfil Batalla, Guillermo (1990). México profundo. Una civilización negada. CNCA/Grijalbo.

Casas Pérez, María de la Luz (1996). "Democratización y cultura en México. Modernización, identidad nacional y resistencia cultural", en Revista Mexicana de Ciencias Políticas y Sociales. Año XLI. Número 166 octubrediciembre.

Casas Pérez, María de la Luz (1998). "Consideraciones metodológicas en torno a la globalización y la comunicación", en Revista Mexicana de Ciencias Políticas y Sociales. UNAM. Año XLIII Número 171 enero-marzo.

Castoriadis, Cornelius (2001). "Visiones sobre el México finisecular", en: Metapolítica. Vol. 5. Núm. 18. Abril/junio

Coatsworth y Rico (1989). Imágenes de México en Estados Unidos. México, Fondo de Cultura Económica.

Fishbein y Azjen (1975). Belief, attitude, intention and behavior: An introduction to theory and research. Addison-Wesley Publishing Co.

García Canclini, Néstor (1990). Culturas híbridas. Estrategias para entrar y salir de la modernidad. CNCA-Grijalbo. 
138 Identidades culturales, globalidad y sociedad de la información

García Canclini, Néstor (1999). La globalización imaginada. Paidós.

Giddens, Anthony (2000). Un mundo desbocado. Los efectos de la globalización en nuestras vidas. Editorial Taurus.

Huntington, Samuel P (1996). The Clash of Civilizations and the Remaking of the World Order. Simon and Schuster.

Margulis, Mario y Marcelo Urresti (comps) (1997). "La cultura en la Argentina de fin de siglo. Ensayos sobre la dimensión cultural". Oficina de publicaciones del CBC. Universidad de Buenos Aires.

Mattelart, Armand (1997). La comunicación mundo. Historia de las ideas y de las estrategias, México, Siglo XXI. 